\title{
From hydroelectric power to Fontan assistance: (R)evolution of the turbine
}

\author{
William M. DeCampli, MD, PhD
}

\author{
From the Division of Cardiothoracic Surgery, Arnold Palmer Hospital for Children, Orlando, Fla; and Department \\ of Clinical Sciences, University of Central Florida College of Medicine, Orlando, Fla. \\ Disclosures: Author has nothing to disclose with regard to commercial support. \\ Received for publication March 2, 2018; accepted for publication March 7, 2018; available ahead of print April \\ $12,2018$. \\ Address for reprints: William M. DeCampli, MD, PhD, Arnold Palmer Hospital for Children, 83 West Miller St, \\ Orlando, FL 32813 (E-mail: William.decampli@ucf.edu). \\ J Thorac Cardiovasc Surg 2018;156:289-90 \\ $0022-5223 / \$ 36.00$ \\ Copyright (c) 2018 by The American Association for Thoracic Surgery \\ https://doi.org/10.1016/j.jtcvs.2018.03.044
}

There may be no greater source of alarm among pediatric cardiologists and surgeons than the increasing evidence that the Fontan circulation will fail in most patients at some point in time. ${ }^{1}$ In a recent article from the Hospital for Sick Children, death was nearly always preceded by a Fontan-related complication (Figure 1). ${ }^{2}$ Among those alive, the Kaplan-Meier freedom from late Fontan complications was only $31 \%$ at 20 years after operation, with persistent hazard. ${ }^{2}$ The present era has been characterized by aggressive attempts to understand the pathophysiology and improve the Fontan strategy and treat complications. 3,4

Among these attempts are ways to mechanically "assist" the Fontan circulation. In this issue of the Journal, Pekkan and coworkers ${ }^{5}$ describe a prototype device - a turbine-type pump that uses the energy of the ventricle to add energy to the Fontan. The device consists of 2 chambers, with a turbine in the first and a propeller in the second. The inlet to the first chamber admits flow from a graft connected to the aorta, and its outlet drains into the atrium. The rotation of its turbine is transmitted to the propeller in the second chamber by an axle. The second chamber's inlet is inferior vena cava flow, and the outlet is the pulmonary arteries.

A simple calculation estimates the ideal effect of this pump. The power in the first chamber is just the pressure decrease (eg, $70 \mathrm{~mm} \mathrm{Hg}$ ) times the shunt flow (eg, 10\% cardiac output). If all of this power is transmitted to the Fontan flow (equal to, eg, 3/4 of cardiac output), then the pressure decrease will be $9 \mathrm{~mm} \mathrm{Hg}$. Pekkan and colleagues' ${ }^{5}$ benchtop simulations showed the pump could indeed achieve a $10 \mathrm{~mm} \mathrm{Hg}$ or more decrease in "caval" pressure.

The idea of using the native ventricle to assist or power the Fontan circulation is not new. It is the paradigm upon which the "injection jet" has been modeled to power both the Fontan and Glenn circulations. ${ }^{6-8}$ The efficiency of the injection jet is sensitive to geometry and is also challenged by viscous energy loss, two features that may be improved on by using a turbine. On the other hand, the performance of Pekkan and colleagues, $^{5}$ new device will ultimately depend on

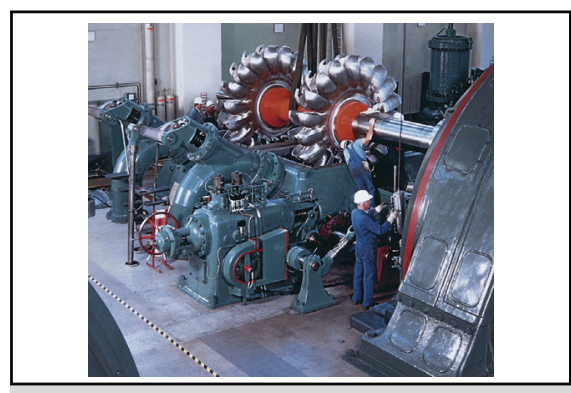

Turbines have many applications. Is the Fontan one of them?

\section{Central Message}

A new gizmo may transfer ventricular energy efficiently to power the Fontan, but the true test will be in vivo.

See Article page 292.

developing more realistic models of the Fontan circulation, the current benchtop modeling being only proof of concept. Although the efficiency of hydraulic turbines with high flow may be upwards of $90 \%$, it is not clear what the efficiency of the present device will be in vivo. In addition, clinicians will have a few other concerns. First, the device as presented appears relatively bulky and may be challenging to position without impinging on the atrial wall. Second, the device design requires placement of 2 synthetic

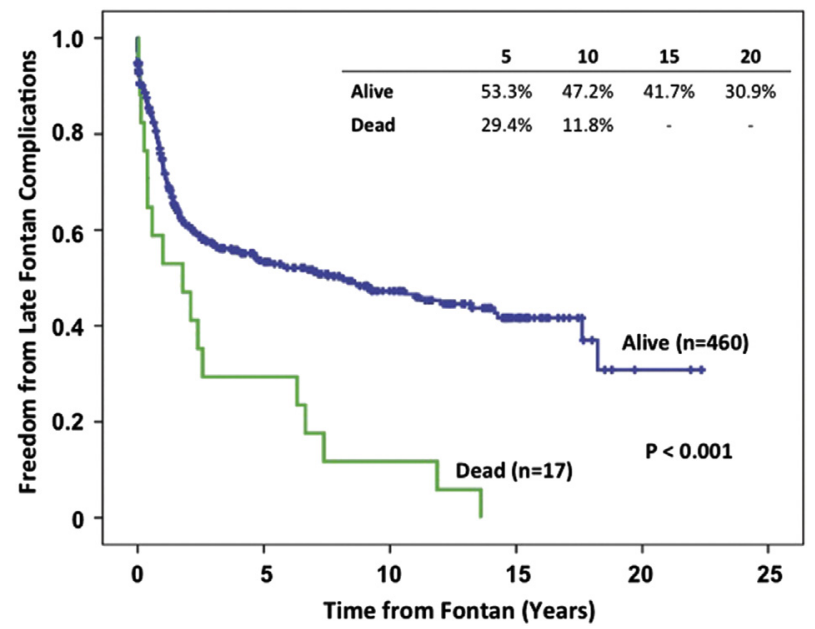

FIGURE 1. Kaplan-Meier freedom from late Fontan complications stratified by mortality (blue curve-alive; green curve-dead) after hospital discharge. Among living patients, the 20-year freedom from complications is $31 \%$. Figure 3 of Kotani and colleagues ${ }^{2}$ used with permission. 
components, one in each side of the circulation, subjecting both to a yet unknown risk of thrombosis and embolism. Third, a jammed propeller may be fatal.

Of course, all of the methods proposed to "assist" the Fontan circulation may be limited to only a subset of patients receiving the Fontan. For those with pulmonary vascular disease, decreased ventricular function, high aortopulmonary collateral burden, or established end-organ complications, the therapy may not be effective. In the absence of better alternatives, however, all of these methods should continue to be investigated and developed.

\section{References}

1. Rychik J. Forty years of the Fontan operation: a failed strategy. Semin Thorac Cardiovasc Surg. 2016;19:37-43.
2. Kotani Y, Chetan D, Zhu J, Saedi A, Zhao L, Mertens L, et al. Fontan failure and death in contemporary Fontan circulation: analysis from the last two decades. Ann Thorac Surg. 2018;105:1240-7.

3. Gewillig M, Brown SC. The Fontan circulation after 45 years: update in physiology. Heart. 2016;102:1081-6.

4. Kreutzer C, Kreutzer G. The lymphatic system: the Achilles heel of the FontanKreutzer circulation. World J Pediatr Congenit Heart Surg. 2017;8:613-23.

5. Pekkan K, Aka IB, Tutsak E, Emek E, Balim H, Lazoglu I, et al. In vitro validation of a self-driving aortic-turbine venous-assist device for Fontan patients. J Thorac Cardiovasc Surg. 2018;156:292-301.e7.

6. DeCampli W. The steam locomotive makes a comeback: a new solution to staged single-ventricle palliation? J Thorac Cardiovasc Surg. 2015;149: 706-7.

7. Esmaily-Moghadam M, Hsia TY, Marsden AL. The assisted bidirectional Glenn: a novel surgical approach for first-stage single-ventricle heart palliation. J Thorac Cardiovasc Surg. 2015;149:699-705.

8. Ni MW, Prather RO, Rodriguez G, Quinn R, Divo E, Fogel M, et al. Computational investigation of a self-powered Fontan circulation. Cardiovasc Eng Technol. February 20, 2018 [Epub ahead of print]. 